\title{
PRODUÇÃO DA CAPUCHINHA EM CULTIVO SOLTEIRO E CONSORCIADO COM OS REPOLHOS VERDE E ROXO SOB DOIS ARRANJOS DE PLANTAS ${ }^{1}$
}

\author{
Yield of nasturtium in monocrop and intercropped with 'green' and 'purple' \\ cabbage under two arrangements of plants
}

\author{
Ademir Antunes Moraes², Maria do Carmo Vieira³, Néstor Antonio Heredia Zárate ${ }^{4}$, \\ Itamar Rosa Teixeira ${ }^{5}$, Edson Talarico Rodrigues ${ }^{6}$
}

\begin{abstract}
RESUMO
Objetivou-se, neste trabalho, estudar a produção de flores da capuchinha e das "cabeças" do repolho, cultivadas como culturas solteiras e consorciadas. Foi estudada a capuchinha 'Jewel' (Ca), em cultivo solteiro e consorciado com os repolhos de folhas verdes 'Sooshu' (RV) ou roxas 'Red Extra Early' (RR), sob duas (2) ou três (3) fileiras de plantas no canteiro. Os dez tratamentos resultantes $\left(\mathrm{Ca}_{2}, \mathrm{Ca}_{3}, \mathrm{RV}_{2}, \mathrm{RV}_{3}, \mathrm{RR}_{2}, \mathrm{RR}_{3}, \mathrm{Ca}_{2} \mathrm{RV}_{3}, \mathrm{Ca}_{3} \mathrm{RV}_{2}, \mathrm{Ca}_{2} \mathrm{RR}_{3}, \mathrm{Ca}_{3} \mathrm{RR}_{2}\right)$ foram arranjados no delineamento experimental blocos casualizados, com três repetições. As colheitas das flores da capuchinha foram efetuadas entre 30 e 155 dias após o transplante (DAT) e as das "cabeças" dos repolhos, entre 102 e 140 DAT. O maior número de flores e a maior massa fresca das flores da capuchinha foi em cultivo solteiro (12.022.220 ha- e 8,20 t ha-1, respectivamente). No consórcio, os maiores valores foram com o repolho roxo (7.555.560 ha $\mathrm{ha}^{-1}$ e 5,04 t ha ${ }^{-1}$, respectivamente). As produções médias de massas fresca das "cabeças" do repolho com folhas verdes em cultivo solteiro e consorciado foram de 33,78 e $35,76 \mathrm{tha}^{-1}$ e do repolho roxo foram de 23,19 e $19,50 \mathrm{t} \mathrm{ha}^{-1}$, respectivamente. O cálculo da razão de área equivalente foi de 1,56 $\left(\mathrm{Ca}_{2} \mathrm{RV}_{3}\right), 1,33\left(\mathrm{Ca}_{3} \mathrm{RV} \mathrm{V}_{2}\right), 1,30\left(\mathrm{Ca}_{2} \mathrm{RR}_{3}\right)$ e $1,45\left(\mathrm{Ca}_{3} \mathrm{RR}_{2}\right)$, indicando ser viável cultivar em consórcio. Considerando a renda bruta, pode-se concluir que o consórcio da capuchinha e do repolho foi viável para o produtor de repolho, devendo optar-se pelo arranjo $\mathrm{Ca}_{2} \mathrm{RV}_{3}$. O produtor de capuchinha deve optar pelo cultivo solteiro, com duas fileiras no canteiro.
\end{abstract}

Termos para indexação: Brassica oleracea var. capitata, Tropaeolum majus, associação de culturas.

\section{ABSTRACT}

This work has as aim to study yield of nasturtium flowers and of cabbage 'heads' that were cultivated as monocrops and intercrops. 'Jewel' nasturtium (Ca) was studied in monocrop and intercropped with 'Sooshu' green leaves (RV) or 'Red Extra Early' purple leaves (RR) cabbages, under two (2) or three (3) rows of plants per plot. The ten resultant treatments $\left(\mathrm{Ca}_{2}, \mathrm{Ca}_{3}, \mathrm{RV}_{2}, \mathrm{RV}_{3}\right.$, $\mathrm{RR} 2, \mathrm{RR}_{3}, \mathrm{Ca}_{2} \mathrm{RV}_{3}, \mathrm{Ca}_{3} \mathrm{RV}_{2}, \mathrm{Ca}_{2} \mathrm{RR}_{3}, \mathrm{Ca}_{3} \mathrm{RR}_{2}$ ) were arranged in a randomized block experimental outline, with three replications. Harvests of nasturtium flowers were between 30 and 155 days after transplant (DAT) and the ones of cabbages between 102 and 140 DAT. The highest number and the greatest fresh mass of nasturtium flowers $\left(12,022,220 \mathrm{ha}^{-1}\right.$ and $8.20 \mathrm{tha}^{-1}$, respectively) were

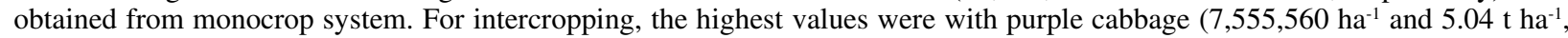
respectively. Average yields of fresh mass of cabbage plants of green leaves in monocrop system and intercropped were of 33.78 and $35.76 \mathrm{t} \mathrm{ha}^{-1}$ and of plants with purple leaves were of 23.19 and $19.50 \mathrm{tha}^{-1}$, respectively. Land Equivalent Ratios were $1.56\left(\mathrm{Ca}_{2} \mathrm{RV}_{3}\right)$, $1.33\left(\mathrm{Ca}_{3} \mathrm{RV}_{2}\right), 1.30\left(\mathrm{Ca}_{2} \mathrm{RR}_{3}\right)$ and $1.45\left(\mathrm{Ca}_{3} \mathrm{RR}_{2}\right)$, what indicates that is viable to cultivate in monocrop system. Considering the gross income one may conclude that the intercrop of nasturtium and cabbage was viable for cabbage producer, who must opt for the $\mathrm{Ca}_{3} \mathrm{RR}_{2}$ arrangement. For nasturtium producer, the monocrop system with two rows per plot was the best.

Index terms: Brassica oleracea var. capitata, Tropaeolum majus, crop association.

(Recebido em 13 de julho de 2006 e aprovado em 26 de março de 2007)

\section{INTRODUÇÃO}

A capuchinha (Tropaeolum majus L.) é uma planta medicinal com ação antiescorbútica, antisséptica, tônica, expectorante, purgante, antiespasmódica, desinfetante das vias urinárias, digestiva e antidepressiva. Como hortaliça, tem toda a parte aérea comestível, incluindo caule, folhas, flores, botões florais e frutos verdes. Folhas e flores são

\footnotetext{
${ }^{1}$ Parte da tese de doutorado do primeiro autor, apresentada à Universidade Federal de Mato Grosso do Sul, para obtenção do título de doutor em Agronomia - Produção Vegetal

Engenheiro Agrônomo, Doutor em Produção Vegetal - Faculdade de Ciências Agrárias/FCA - Universidade Federal da Grande Dourados/UFGD Rodovia Dourados a Ithaum, Km 12 - Cx. P. 533 - 79804-970 - Dourados, MS - a.antunes@ufgd.edu.br

${ }^{3}$ Engenheira Agrônoma, Doutora, Professora Titular - Faculdade de Ciências Agrárias/FCA - Universidade Federal da Grande Dourados/UFGD Rodovia Dourados a Ithaum, Km 12 - Cx. P. 533 - 79804-970 - Dourados, MS - mcvieira@ufgd.edu.br - Bolsista de Produtividade em Pesquisa do CNPq ${ }^{4}$ Engenheiro Agrônomo, Doutor, Professor Associado I - Faculdade de Ciências Agrárias/FCA - Universidade Federal da Grande Dourados/UFGD Rodovia Dourados a Ithaum, Km 12 - Cx. P. 533 - 79804-970 - Dourados, MS - nheredia@ufgd.edu.br - Bolsista de Produtividade em Pesquisa do CNPq ${ }^{5} \mathrm{PhD}$ - Departamento de Ciências Agrárias - Universidade Estadual de Goiás/UEG - Rodovia GO 330, Km 241 - Anel Viário - $75780-000$ - Ipameri, GO itamar.teixeira@ueg.br

${ }^{6}$ Doutor - Unidade Universitária de Aquidauana/UUA - Universidade Estadual de Mato Grosso do Sul/UEMS - Rodovia Aquidauana, CEPA, Km 12 - Área Rural - Cx. P. 25 - 79200-000 - Aquidauana, MS - etalarico@gmail.com
} 
fontes de vitamina $\mathrm{C}$ e sais minerais como nitrogênio, enxofre, iodo, ferro, potássio e fosfatos e podem ser utilizadas em saladas. As flores possuem vários pigmentos naturais do grupo dos carotenóides e também um corante chamado sorbusina, utilizado na indústria alimentícia. Os botões florais e os frutos verdes preparados em conservas com vinagre e sal são bastante consumidos na Europa e conhecidos como alcaparras da Índia ou alcaparras do campo (FONT QUER, 1993; ZANETTI, 2001). Carlson \& Kleiman (1993) citam que o óleo produzido pelas sementes, conhecido no mundo inteiro como óleo de Lorenzo, é usado para o tratamento da adrenoleucodistrofia (ADL), doença grave e degenerativa.

As plantas de capuchinha são ervas ou lianas herbáceas, freqüentemente suculentas; as folhas são alternadas e simples. As flores são axilares; vistosas, bissexuadas, zigomorfas; cálice pentâmero, com as três sépalas inferiores unidas formando uma espora, com tecido nectarífero em seu interior; corola pentâmera, dialipétala, pétalas ungüiculadas, oito estames; ovário súpero, trilocular e lóculos uniovulados; fruto esquizocárpico (SOUZA \& LORENZI, 2005). Microscopicamente, as raízes são do tipo tetrarca, com crescimento secundário na base do caule. O cilindro central é contínuo, com o floema voltado para fora. A folha é dorsiventral e anfiestomática (CASTELLANI, 1997).

A planta de capuchinha é recomendada como companheira para cultivo com outras espécies, pela sua característica de atrair lepidópteros, repelir pulgões e besouros, melhorar o crescimento e o sabor de outras plantas, como de rabanete (Raphanus sativus L.), repolho (Brassica oleracea var. capitata L.), tomate (Lycopersicum esculentum Mill.) e pepino (Cucumis sativus L.) (LACABUENDIA \& BRANDÃO, 1988); é também planta melífera (COMBA et al., 1999) e ornamental (LORENZI \& MATOS, 2002). Considerando essas características agronômicas, seu cultivo poderia ser alternativa para os produtores de hortaliças, principalmente em consórcio com o repolho, visando a produção de flores, para serem consumidas como hortaliça.

O repolho, além das diversas propriedades nutritivas, apresenta teores altos de cálcio e fósforo. É um alimento muito versátil à mesa e na indústria, podendo ser consumido cru, cozido, assado, frito, na forma de chucrute, picles e desidratado. O repolho pode ser cultivado ao longo do ano, sendo a temperatura ótima para o desenvolvimento da planta de $23^{\circ} \mathrm{C}$, exceto para as cultivares de outonoinverno, que é de 15 a $21^{\circ} \mathrm{C}$ (FILGUEIRA, 2000; SILVA JÚNIOR, 1989).
O sistema de cultivo misto ou intercalado, em horticultura, tem despertado a atenção de pesquisadores, principalmente pela riqueza das interações ecológicas, do arranjo e manejo da cultura e da importância econômica. Sobre o consórcio de hortaliças com plantas medicinais, embora encontrem-se algumas citações, como por exemplo, capuchinha e macieira (CORRÊA, 1984) e capuchinha e repolho (LACA-BUENDIA \& BRANDÃO, 1988; MORAES et al., 2005), é ainda pouco pesquisado. Tornam-se necessárias, portanto, ações para geração de conhecimentos que possam sistematizar a produção comercial, principalmente para viabilizar o aproveitamento racional dos recursos escassos nas pequenas propriedades.

No trabalho de Moraes et al. (2005), foram avaliadas a produção de "cabeças" de repolho e de flores da capuchinha, em função do consórcio das duas espécies, com ou sem o uso de cama-de-frango semidecomposta. As produções de repolho foram de $32,76 \mathrm{t} \mathrm{ha}^{-1}$ no arranjo em cultivo solteiro e de $27,65 \mathrm{t} \mathrm{ha}^{-1}$ no cultivo consorciado e de $35,78 \mathrm{t} \mathrm{ha-}^{-1}$ e $24,62 \mathrm{t} \mathrm{ha-}^{-1}$, com e sem o uso de cama-defrango, respectivamente. A maior produção de capuchinha foi sem o uso de cama-de-frango, em cultivo solteiro, com 15.825.000 flores e 10,63 $\mathrm{t} \mathrm{ha}^{-1}$ de massa fresca. Altura de plantas, diâmetro e comprimento das flores de capuchinha foram influenciados apenas pelas épocas de avaliação. $\mathrm{O}$ cálculo da razão de área equivalente para o consórcio foi de 1,35 com uso de cama-de-frango e de 1,25 sem o uso, indicando ser viável o cultivo misto de repolho com a capuchinha. A renda bruta para o consórcio foi de $\mathrm{R} \$ 38.065,20$ e $\mathrm{R} \$ 28.587,50$ com e sem uso de cama-defrango, respectivamente.

Objetivou-se avaliar, neste trabalho, as produções de flores da capuchinha e de "cabeças" do repolho, cultivadas como culturas solteiras e consorciadas, com duas ou três fileiras de plantas no canteiro, visando oferecer aos agricultores novas alternativas produtivas e sustentáveis.

\section{MATERIAL E MÉTODOS}

O experimento foi desenvolvido no Horto de Plantas Medicinais - HPM, da Universidade Federal de Mato Grosso do Sul - UFMS, em Dourados, no período de abril a setembro de 2003. O Município de Dourados situa-se em latitude de $22^{\circ} 13^{\prime} 16^{\prime \prime S}$, longitude de $54^{\circ} 17^{\prime} 01^{\prime \prime} \mathrm{W}$ e altitude de $452 \mathrm{~m}$. O clima da região, segundo a classificação de Köppen, é Mesotérmico Úmido, do tipo Cwa, com temperaturas e precipitações médias anuais variando de $20^{\circ}$ a $24^{\circ} \mathrm{C}$ e 1250 a $1500 \mathrm{~mm}$, respectivamente. No período do ciclo da cultura, a temperatura média foi de cerca de $32^{\circ} \mathrm{C}$. O solo, onde se implantou o experimento é do tipo 
Latossolo Vermelho distroférrico, cujas características químicas encontradas foram: $\mathrm{pH}$ em água $(1: 2,5): 5,3 ; \mathrm{Al}^{+3}$, $\mathrm{K}, \mathrm{Mg}$, e $\mathrm{Ca}\left(\mathrm{mmol} \mathrm{dm}^{-3}\right): 7,8 ; 1,7 ; 13,7 ; 29,9$, respectivamente; P mg dm ${ }^{-3}$ : 8,0; soma de bases: $45,3 \mathrm{mmol}_{\mathrm{c}} \mathrm{dm}^{-3}$; capacidade de troca de cátions: $117,3 \mathrm{mmol}_{\mathrm{c}} \mathrm{dm}^{-3}$; M.O: $26,6 \mathrm{~g} \mathrm{dm}^{-3}$.

Foi estudada a capuchinha 'Jewel' (Ca) e o repolho 'Sooshu' de folhas verdes (RV) e o 'Red Extra Early' de folhas roxas (RR), em cultivo solteiro e consorciado, sob duas (2) ou três (3) fileiras de plantas no canteiro. Os dez tratamentos resultantes $\left(\mathrm{Ca}_{2}, \mathrm{Ca}_{3}, \mathrm{RV}_{2}, \mathrm{RV}_{3}, \mathrm{RR}_{2}, \mathrm{RR}_{3}\right.$, $\mathrm{Ca}_{2} \mathrm{RV}_{3}, \mathrm{Ca}_{3} \mathrm{RV}_{2}, \mathrm{Ca}_{2} \mathrm{RR}_{3}, \mathrm{Ca}_{3} \mathrm{RR}_{2}$ ) foram arranjados no delineamento experimental blocos casualizados, com três repetições.

A capuchinha e o repolho foram propagados por sementes, e o semeio feito em 25 de abril. A capuchinha foi semeada em sacos de polietileno preto de $17 \times 10 \mathrm{~cm}$, preenchidos com substrato preparado com solo da área, cama-de-frango e areia fina lavada, nas proporções 3:1:1. O repolho foi semeado em bandejas de isopor de 128 células, preenchidas com o substrato comercial Plantmax, todos colocados em ambiente protegido. A área experimental foi preparada com aração, gradagem e levantamento de canteiros com rotoencanteirador; não foi utilizada nenhuma adubação por ocasião do transplante e nem em cobertura. $\mathrm{O}$ transplante no local definitivo foi feito aos 25 dias após a semeadura, quando as plântulas da capuchinha e do repolho apresentavam alturas em torno de $12 \mathrm{~cm}$ e $8 \mathrm{~cm}$, respectivamente, e 4 a 5 folhas verdadeiras. As parcelas tinham área total de $2,7 \mathrm{~m}^{2}(1,5 \mathrm{~m}$ de largura $\mathrm{x}$ $1,8 \mathrm{~m}$ de comprimento) e área útil de $1,9 \mathrm{~m}^{2}$ (1,1 m de largura $\mathrm{x} 1,8 \mathrm{~m}$ de comprimento). Os espaçamentos entre as duas fileiras de capuchinha ou de repolho foram de $0,54 \mathrm{~m} \mathrm{e}$ entre as três fileiras, de $0,36 \mathrm{~m}$ e entre plantas na linha foram de $0,30 \mathrm{~m}$, correspondendo às populações de 43.956 e 65.934 plantas ha $^{-1}$, respectivamente, das culturas solteiras.

As irrigações foram feitas por aspersão, de duas a três vezes por semana. As capinas foram manuais, em número de três. Não foi feito nenhum tratamento fitossanitário durante o cultivo das plantas. Entre 20 e 70 dias após o transplante, com intervalos de dez dias, foram medidas as alturas de todas as plantas, usando régua de madeira com escala milimétrica.

De todas as plantas da capuchinha, foram colhidas as flores, entre 30 e 155 dias após o transplante - DAT, duas vezes por semana. Avaliaram-se os números e as massas frescas das flores. Foram medidos o comprimento e o diâmetro de dez flores por parcela, utilizando-se do paquímetro, entre 30 e 54 DAT, com intervalos de seis dias. Para a medida do comprimento da flor, foi considerado o desde o ápice das pétalas até a ponta da espora (prolongamento das sépalas da capuchinha). As plantas dos repolhos verde e roxo foram colhidas inteiras, nos mesmos dias, entre 102 (5-8-2003) e 140 DAT (12-9-2003), utilizando-se como indicativo de colheita a perda do brilho das folhas e a compactação completa das "cabeças". As folhas externas foram separadas das "cabeças" e essas foram pesadas para obtenção da massa fresca.

Os dados foram submetidos à análise de variância, separadamente para capuchinha e repolho; quando se detectou significância pelo teste $\mathrm{F}$, as médias foram comparadas pelo teste Tukey, até $5 \%$ de probabilidade. Às médias de alturas de plantas, comprimentos e diâmetros de flores, foram ajustadas equações de regressão (RIBEIRO JÚNIOR, 2001). O consórcio foi avaliado utilizando a expressão da razão de área equivalente (RAE) proposta por Caetano et al. (1999). A validação do consórcio foi mediante a determinação da renda bruta.

\section{RESULTADOS E DISCUSSÃO}

As alturas das plantas da capuchinha não variaram significativamente entre tratamentos, demonstrando que prevaleceu o efeito do componente genético característico da espécie ou a ação de algum componente químico do solo, não determinado, que impediu um "bom" desenvolvimento e crescimento das plantas. Aos 70 dias após o transplante, as plantas tinham altura média de 21,05 $\mathrm{cm}$ e encontravam-se em pleno florescimento (Figura 1a). $\mathrm{O}$ fato de as plantas continuarem a crescer após o início do florescimento indica que na capuchinha o crescimento vegetativo e o desenvolvimento reprodutivo processamse simultaneamente (CASTELLANI, 1997; LARCHER, 2000). O crescimento geral das plantas de capuchinha foi linear no período da avaliação, exceto no consórcio com duas fileiras de repolho verde e com três de repolho roxo, que tiveram tendência quadrática. Sangalli et al. (2004), avaliando o crescimento da capuchinha 'Jewel', associada ao uso de resíduo orgânico, com ou sem nitrogênio, entre 20 e 100 DAT, verificaram que a altura das plantas foi influenciada significativamente pela interação época e resíduos orgânicos.

O diâmetro e o comprimento das flores da capuchinha apresentaram curvas de crescimento quadrático em função dos dias após o transplante (Figura 1b). Os máximos diâmetro $(56,1 \mathrm{~mm})$ e comprimento $(63,8$ $\mathrm{mm}$ ) das flores foram alcançados aos 44 DAT. Esses valores diferem daqueles encontrados por Sangalli et al. (2004), cujos valores foram de 42,7 a $45,7 \mathrm{~mm}$ para diâmetro e de 25 a $26 \mathrm{~mm}$ para o comprimento das flores colhidas entre $70 \mathrm{e}$ 98 DAT. As diferenças nas magnitudes podem estar 
relacionadas com as épocas de avaliação e, especificamente, para o comprimento das flores, com o critério de medição, uma vez que nesse trabalho a medida foi realizada considerando a espora da flor.

A produção de flores da capuchinha teve efeito significativo da interação entre o tipo de cultivo e o arranjo de plantas (Tabela 1). As plantas cultivadas solteiras e com duas fileiras de plantas no canteiro produziram mais flores, tanto em número como em massa fresca, que aquelas sob consórcio, mas foram semelhantes àquelas sob três fileiras. Esse fato está provavelmente relacionado com a manutenção da eficiência na absorção e/ou, no uso da água, dos nutrientes e do $\mathrm{CO}_{2}$, pois na maioria das culturas consorciadas é notada redução de produtividade (SILVA, 1983). Dentro do consórcio, as plantas cultivadas com o

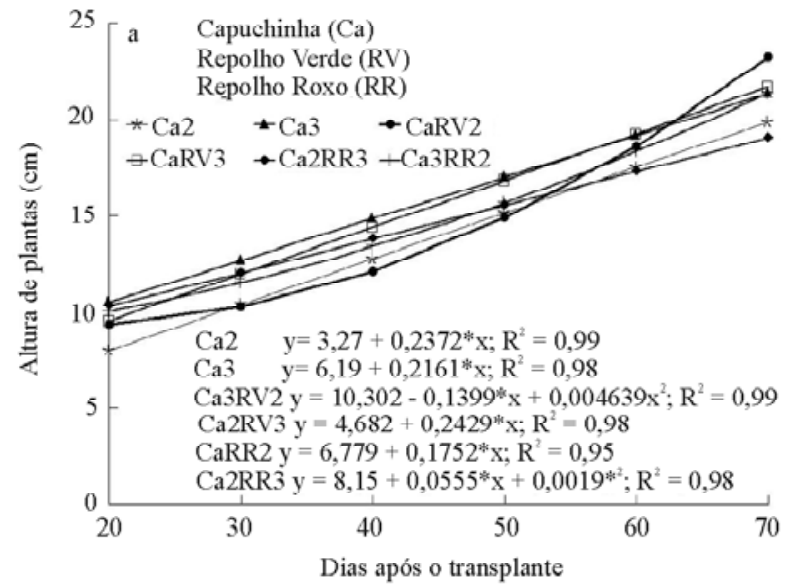

repolho roxo, sob três fileiras de plantas no canteiro, produziram mais flores que aquelas sob duas fileiras (Tabela 1). Esses resultados podem estar relacionados com as características das cultivares de repolho, especialmente com as plantas da cultivar Red Extra Early que, ao apresentarem menor área foliar e menores "cabeças", tiveram pequena adaptação às condições ambientes prevalecentes durante o ciclo do cultivo, e, provavelmente, mais relacionado com a temperatura, cuja média no período do ciclo da cultura foi de $\pm 32^{\circ} \mathrm{C}$. Esse fato concorda com Silva Júnior (1989), ao citar que o repolho roxo é de difícil adaptação aos trópicos. Portanto, as plantas do repolho roxo, ao crescerem menos, apresentaram menor competição para as da capuchinha e, assim, devem ter facilitado, indiretamente, a maior produção de flores da capuchinha.

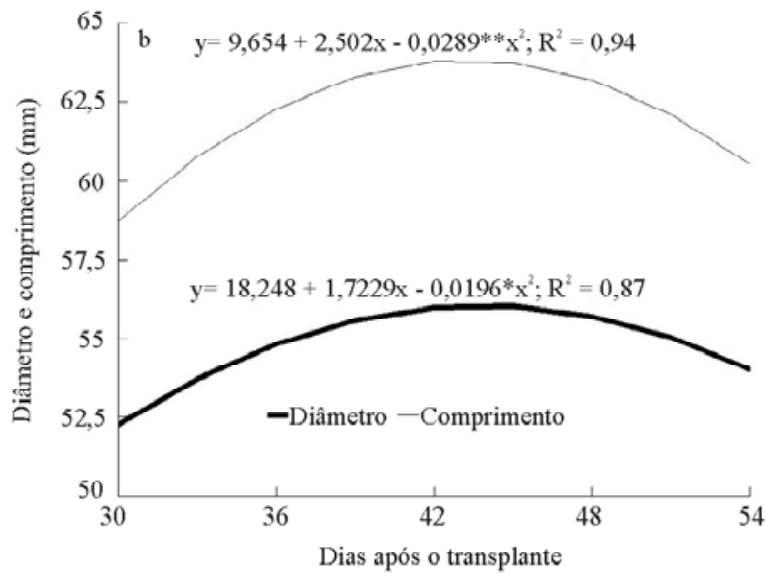

Figura 1 - Altura das plantas (a) e diâmetro e comprimento das flores (b) das capuchinhas, cultivadas solteiras e consorciadas, com repolhos verde e roxo, sob duas ou três fileiras no canteiro, em função de dias após o transplante. Dourados, UFMS, 2003.

Tabela 1 - Número e massa fresca de flores da capuchinha 'Jewel', em cultivo solteiro e consorciado com repolho, arranjados em duas ou três fileiras no canteiro. Dourados, UFMS, 2003.

\begin{tabular}{|c|c|c|c|c|c|}
\hline \multirow{3}{*}{ Arranjo } & \multirow{3}{*}{$\begin{array}{l}\text { Tipo de } \\
\text { Repolho }\end{array}$} & \multicolumn{2}{|c|}{ Flores (número ha ${ }^{-1}$ ) } & \multicolumn{2}{|c|}{ Massa fresca $\left(\mathrm{kg} \mathrm{ha}^{-1}\right)$} \\
\hline & & \multicolumn{2}{|c|}{ Fileiras no canteiro } & \multicolumn{2}{|c|}{ Fileiras no canteiro } \\
\hline & & Duas & Três & Duas & Três \\
\hline \multirow{2}{*}{\multicolumn{2}{|c|}{$\begin{array}{l}\text { Solteiro } \\
\text { Consórcio }\end{array}$}} & $12.022 .220 \mathrm{a}$ & $11.555 .560 \mathrm{a}$ & $8,20 \mathrm{a}$ & $7,71 \mathrm{a}$ \\
\hline & & $5.000 .000 \mathrm{~b}$ & $6.100 .000 \mathrm{~b}$ & $3,21 \mathrm{a}$ & $4,11 \mathrm{~b}$ \\
\hline \multirow[b]{2}{*}{ Consórcio } & Verde & $4.777 .780 \mathrm{~A}$ & $4.644 .440 \mathrm{~A}$ & $3,04 \mathrm{~A}$ & $3,18 \mathrm{~A}$ \\
\hline & Roxo & $5.222 .220 \mathrm{~B}$ & $7.555 .560 \mathrm{~A}$ & $3,38 \mathrm{~B}$ & $5,04 \mathrm{~A}$ \\
\hline \multicolumn{2}{|c|}{ C.V. (\%) } & \multicolumn{2}{|c|}{11,66} & \multicolumn{2}{|c|}{12,51} \\
\hline
\end{tabular}

Médias seguidas pelas mesmas letras, minúsculas nas colunas e maiúsculas nas linhas, dentro de cada característica, não diferem, pelo teste Tukey, a 5\% de probabilidade. 
As alturas das plantas dos repolhos de folhas verdes e roxas (Figura 2) apresentaram crescimento linear, com taxas variáveis e dependentes do tipo em estudo. Essa tendência linear deve ter relação com o período das mensurações, feitas entre 20 e 70 DAT, uma vez que, segundo Filgueira (2000), colhem-se as "cabeças" de repolho quando, ao fim do ciclo de 80 a 100 dias, elas se apresentarem bem formadas e compactas. Nas condições em que foi conduzido o experimento, as plantas dos repolhos verde e roxo foram colhidas entre 102 (5-8-2003) e 140 DAT (12-9-2003), ou seja, com comportamento de ciclo médio para tardio. A mudança no ciclo vegetativo das plantas, em relação à literatura, mostra que houve a ação de algumas condições edafoclimáticas não determinadas. Em geral, as plantas consorciadas foram mais altas que aquelas sob cultivo solteiro. Esses resultados estão de acordo com Carneiro (1981), que cita a tendência de o repolho em cultivo consorciado, crescer mais em altura do que em diâmetro, isso modificado pela densidade populacional. Quanto ao crescimento menor do repolho de folhas roxas em relação ao de folhas verdes, no consórcio, pode ser devido a características adaptativas da cultivar (LARCHER, 2000).

A produção do repolho foi influenciada significativamente pela interação entre o sistema de cultivo e o tipo de repolho e pelo número de fileiras no canteiro. Em geral, as produções de massa fresca das plantas do repolho com folhas verdes foram maiores que as do repolho com folhas roxas, tanto no cultivo solteiro como no consórcio com a capuchinha (Tabela 2). Esses resultados podem ser explicados pelas características das cultivares, ou seja, as roxas são de difícil aclimatação nos trópicos; isso, apesar de a Red Extra Early ser a mais cultivada no
Brasil, ter ciclo de 120 a 130 dias e as "cabeças" pesarem em média $850 \mathrm{~g}$. Por outro lado, as cultivares verdes em geral, são próprias para os trópicos, sendo a Sooshu uma das que tolera até $38^{\circ} \mathrm{C}$ e suas "cabeças" terem massa média de 2,0 kg (SILVA JÚNIOR, 1989).

As produções médias obtidas nos sistemas testados para massa fresca das "cabeças" dos repolhos de folhas verdes e de folhas roxas foram de $34,77 \mathrm{t} \mathrm{ha}^{-1} \mathrm{e}$ $21,35 \mathrm{tha}^{-1}$, respectivamente. Esses valores foram maiores que os relatados por Nunes et al. (2004), que estudando cultivares de repolho verde, em sistema orgânico e em cultivo solteiro, obtiveram produção média de $15,45 \mathrm{t} \mathrm{ha}^{-1}$ de massa fresca total do produto comercial; mas, foram inferiores aos obtidos por Carneiro (1981) que, estudando o cultivo consorciado de repolho e alface, no espaçamento de $0,60 \mathrm{~m}$ entre linhas e $0,25 \mathrm{~m}$ entre plantas, encontraram produções médias de $71,80 \mathrm{t} \mathrm{ha}^{-1}$ e $44,34 \mathrm{t} \mathrm{ha}^{-1}$, no cultivo solteiro e no consorciado, respectivamente. Essa diferença pode justificar-se pelos tratos culturais empregados por Carneiro (1981) que aos 15 e 50 DAT, aplicou $20 \mathrm{~g}$ por vez e por planta, de sulfato de amônia, e, aos 40 DAT pulverizou a cultura do repolho com uma solução de bórax a $0,5 \%$, enquanto nesse estudo não foi utilizada nenhuma adubação orgânica ou química.

A produção média de massa fresca das "cabeças" do repolho obtida com três fileiras de plantas por canteiro $\left(32,90 \mathrm{t} \mathrm{ha}^{-1}\right)$ superou em 9,68 $\mathrm{t} \mathrm{ha}^{-1}$ à obtida com duas fileiras, mas a massa de cada "cabeça" ( $499,0 \mathrm{~g})$ teve $29,3 \mathrm{~g}$ a menos que a obtida com duas fileiras $(528,3 \mathrm{~g})$. A redução da produção sob maior pressão populacional deve ter sido consequiência da competição por fatores de crescimento, tais como luz, nutrientes e água. Isso pode ser confirmado pela baixa fertilidade do solo, somada ao $\mathrm{pH}$ em água de
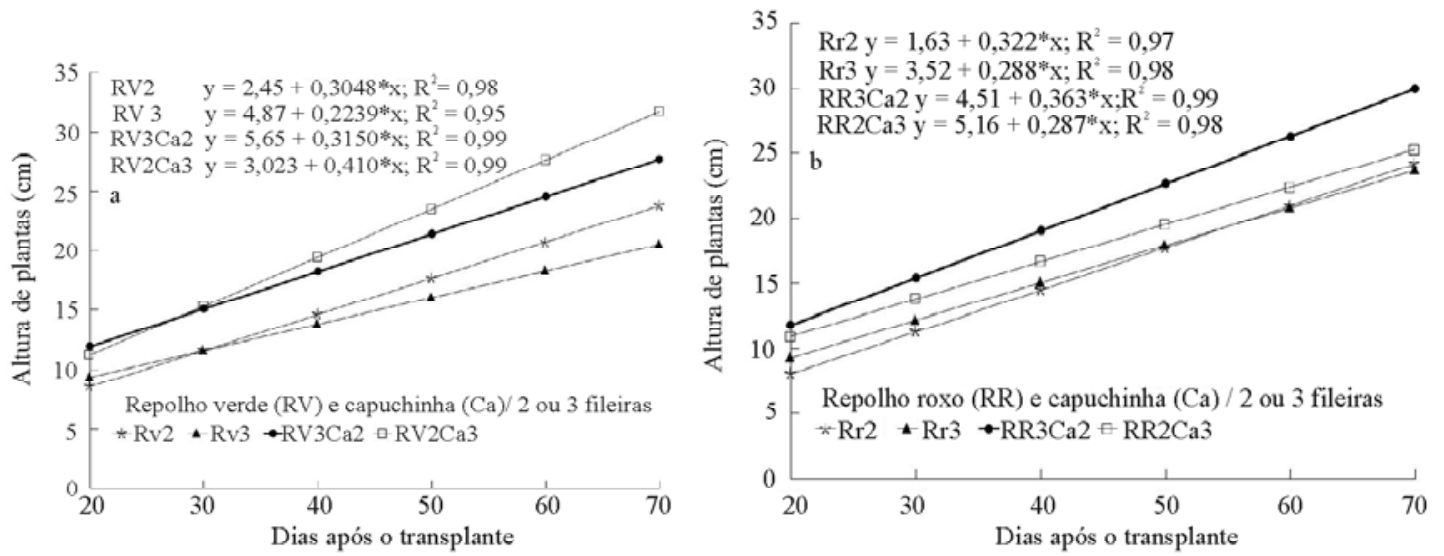

Figura 2 - Altura das plantas do repolho de folhas verdes (a) e roxas (b), solteiras e consorciadas com capuchinha, sob duas ou três fileiras no canteiro, em função de dias após o transplante. Dourados, UFMS, 2003. 
Tabela 2 - Massas frescas das "cabeças" de dois tipos de repolho, em cultivo solteiro e em consórcio com a capuchinha 'Jewel', sob duas ou três fileiras no canteiro. Dourados-UFMS, 2003.

\begin{tabular}{|c|c|c|c|c|}
\hline \multirow{3}{*}{$\begin{array}{c}\text { Sistema } \\
\text { de cultivo }\end{array}$} & \multirow{3}{*}{ Tipo de repolho } & \multicolumn{3}{|c|}{ Massa fresca $\left(\mathrm{t} \mathrm{ha}^{-1}\right)$} \\
\hline & & \multicolumn{2}{|c|}{ Fileiras no canteiro } & \multirow{2}{*}{ Média } \\
\hline & & 2 & 3 & \\
\hline \multirow{2}{*}{ Solteiro } & Verde & 28,88 & 38,68 & $33,78 \mathrm{a}$ \\
\hline & Roxo & 20,68 & 25,71 & $23,19 b$ \\
\hline \multirow{2}{*}{ Consórcio } & Verde & 26,79 & 44,73 & $35,76 \mathrm{a}$ \\
\hline & Roxo & 16,53 & 22,48 & $19,50 \mathrm{~b}$ \\
\hline \multicolumn{2}{|c|}{ Média } & $23,22 \mathrm{~B}$ & $32,90 \mathrm{~A}$ & \\
\hline \multicolumn{2}{|c|}{ C.V. $(\%)$} & \multicolumn{2}{|c|}{11,71} & \\
\hline
\end{tabular}

Médias seguidas pelas mesmas letras minúscula, na coluna e maiúscula na linha, não diferem entre si, pelo teste $\mathrm{F}$, a $5 \%$ de probabilidade.

5,3 , aquém do recomendado para a cultura do repolho (FILGUEIRA, 2000), além da não utilização de qualquer adubação orgânica ou química, nesse trabalho, que podem ser a causa da pequena massa das "cabeças".

A razão de área equivalente - RAE para os consórcios da capuchinha com o repolho de folhas verdes e da capuchinha com repolho de folhas roxas, cultivadas com duas ou três fileiras de plantas no canteiro, considerando as produtividades de massa fresca das culturas, foi de 1,56 para $\mathrm{Ca}_{2} \mathrm{RV}_{3} ; 1,33$ para $\mathrm{Ca}_{3} \mathrm{RV}_{2} ; 1,30$ para $\mathrm{Ca}_{2} \mathrm{RR}_{3}$, e 1,45 para $\mathrm{Ca}_{3} \mathrm{RR}_{2}$ (Tabela 3 ). Pelo fato de os valores da RAEs terem sido superiores a 1,0, conclui-se que os consórcios foram efetivos e que podem ser recomendados. As diferenças entre os valores das RAEs confirmam a consideração de Sullivan (2003), de que é possível variar as culturas envolvidas, a população total, a densidade populacional de cada cultura e o arranjo das culturas dentro do consórcio.

Perante a inexistência de determinações de custos de produção para as culturas consorciadas feitas com hortaliças, o que impede a determinação da maioria de índices de resultado econômico, optou-se por relacionar a produtividade e a renda bruta da capuchinha, cultura principal do trabalho, e dos repolhos de folhas verde e roxa. Ao relacionar a renda bruta (Tabela 3), observou-se que, para o produtor de capuchinha, foi melhor o cultivo solteiro com duas fileiras de plantas no canteiro ( $\mathrm{R} \$ 24.040,00)$, já que poderia ter induzido incrementos monetários de $\mathrm{R} \$ 930,00$ em relação ao cultivo com três fileiras de plantas, e entre $\mathrm{R} \$ 600,00$ e $\mathrm{R} \$ 7.180,00$ em relação aos consórcios $\mathrm{Ca}_{3} \mathrm{RR}_{2}$ e $\mathrm{Ca}_{3} \mathrm{RV}_{2}$, respectivamente.

Para o produtor de repolho, o melhor tratamento foi o consórcio $\mathrm{Ca}_{3} \mathrm{RR}_{2}$, que poderia ter induzido incrementos de $\mathrm{R} \$ 13.380,00$ e $\mathrm{R} \$ 10.580,00$, respectivamente, em relação ao melhor tratamento dos repolhos de folhas verdes ( $\mathrm{R} \$ 10.060,00)$ e de folhas roxas $(\mathrm{R} \$ 12.860,00)$, que foi o cultivo solteiro com três fileiras de plantas no canteiro. Os valores obtidos para as RAEs e para as rendas brutas são coerentes com as citações de Moraes et al. (2005) e Sullivan (2003), confirmando a hipótese de que o aumento da produção é uma das razões mais importantes para se cultivar duas ou mais espécies no sistema de consorciação. 
Tabela 3 - Razão de área equivalente - RAE e Renda bruta da capuchinha e do repolho, considerando a produção de flores de capuchinha e a massa fresca das "cabeças" dos repolhos verde e roxo, em cultivo solteiro e consorciado, sob duas e três fileiras. Dourados-UFMS, 2003.

\begin{tabular}{|c|c|c|c|c|c|c|c|}
\hline \multirow{2}{*}{$\begin{array}{l}\text { Tipo de } \\
\text { cultivo }\end{array}$} & \multirow[t]{2}{*}{ Espécie } & \multirow{2}{*}{$\begin{array}{c}\text { Fileiras } \\
\text { no } \\
\text { canteiro }\end{array}$} & \multirow{2}{*}{$\begin{array}{c}\text { Flores } \\
\left(\text { número ha }^{-1}\right)\end{array}$} & \multirow{2}{*}{$\begin{array}{l}\text { Massa } \\
\text { fresca } \\
\left(\mathrm{t} \mathrm{ha}^{-1}\right)\end{array}$} & \multirow[t]{2}{*}{ RAE } & \multicolumn{2}{|c|}{$\begin{array}{l}\text { Renda bruta } \\
\left(\mathrm{R} \$ 1.000 \mathrm{ha}^{-1}\right)\end{array}$} \\
\hline & & & & & & Cultivo & Total \\
\hline \multirow{6}{*}{ Solteiro } & \multirow{2}{*}{ Capuchinha } & 2 & 12.022 .220 & & 1,00 & $24,04 *$ & 24,04 \\
\hline & & 3 & 11.555 .560 & & 1,00 & 23,11 & 23,11 \\
\hline & \multirow{2}{*}{ Repolho verde } & 2 & & 28,88 & 1,00 & $7,51 * *$ & 7,51 \\
\hline & & 3 & & 38,68 & 1,00 & 10,06 & 10,06 \\
\hline & \multirow{2}{*}{ Repolho Roxo } & 2 & & 20,68 & 1,00 & $10,34 * * *$ & 10,34 \\
\hline & & 3 & & 25,71 & 1,00 & 12,86 & 12,86 \\
\hline Consórcio & Capuchinha & 2 & 4.777 .780 & & & 9,56 & \\
\hline $\mathrm{Ca}_{2} \mathrm{RV}_{3}$ & Repolho verde & 3 & & 44,73 & 1,56 & 11,63 & 21,19 \\
\hline Consórcio & Capuchinha & 3 & 4.644 .440 & & & 9,29 & \\
\hline $\mathrm{Ca}_{3} \mathrm{RV}_{2}$ & Repolho verde & 2 & & 26,79 & 1,33 & 6,97 & 16,26 \\
\hline Consórcio & Capuchinha & 2 & 5.222 .220 & & & 10,44 & \\
\hline $\mathrm{Ca}_{2} \mathrm{RR}_{3}$ & Repolho Roxo & 3 & & 22,48 & 1,30 & 11,24 & 21,68 \\
\hline Consórcio & Capuchinha & 3 & 7.555 .560 & & & 15,17 & \\
\hline $\mathrm{Ca}_{3} \mathrm{RR}_{2}$ & Repolho Roxo & 2 & & 16,53 & 1,45 & 8,27 & 23,44 \\
\hline
\end{tabular}

*Em caixa com 100 flores ao preço de $\mathrm{R} \$ 0,20$ caixa $^{-1} * *$ Em kg ao preço de $\mathrm{R} \$ 0,26 \mathrm{~kg}^{-1} * * *$ Em kg ao preço de $\mathrm{R} \$ 0,50$ $\mathrm{kg}^{-*}$ (Preços tomados no comércio de Dourados, em outubro de 2005).

\section{CONCLUSÕES}

Para o produtor de repolho, foi viável consorciá-lo com a capuchinha. O melhor arranjo do consórcio capuchinha e repolho foi de três fileiras de capuchinha e duas de repolho roxo.

\section{REFERÊNCIAS BIBLIOGRÁFICAS}

CAETANO, L. C. S.; FERREIRA, J. M.; ARAÚJO, M. de. Produtividade da alface e cenoura em sistema de consorciação. Horticultura Brasileira, Brasília, v. 17, n. 2, p. 143-146, 1999.

CARLSON, K. D.; KLEIMAN, R. Chemical survey and erucic acid content of commercial varieties of nasturtium, Tropaeolum majus L. Journal of the American Oil Chemists Society, Champaign, v. 70, n. 11, p. 1145-1148, 1993.

CARNEIRO, I. F. Competição entre a cultura do repolho (Brassica oleracea var. capitata L.) e a cultura da alface (Lactuca sativa L.) em cultivo misto e em diferentes densidades de população. 1981. 69 f. Dissertação (Mestrado em Fitotecnia) - Escola Superior de Agricultura de Luiz de Queiroz, Piracicaba, 1981.

CASTELLANI, D. C. Crescimento, anatomia e produção de ácido erúcico em Tropaeolum majus L. 1997. 108 f. Dissertação (Mestrado em Fitotecnia) - Universidade Federal de Viçosa, Viçosa, 1997.

COMBA, L.; CORBERT, S. A.; BARROM, A.; BIRD, A.; COLLINE, S.; MIYAZAKI, N.; POWELL, M. Garden flowers: insect visits and the floral reward of horticulturally: modified variants. Annals of Botany, Cambridge, v. 83, n. 1, p. 73-86, 1999.

CORRÊA, M. P. Dicionário de plantas úteis do Brasil e das exóticas cultivadas. Rio de Janeiro: Imprensa Nacional, 1984. v. 1, 774 p.

FILGUEIRA, F. A. R. Novo manual de olericultura: agrotecnologia moderna na produção e comercialização de hortaliças. Viçosa: UFV, 2000. 402 p.

FONT QUER, P. Plantas medicinales: el dioscórides renovado. Barcelona: Labor, 1993. v. 2, 637 p. 
LACA-BUENDIA, J. P.; BRANDÃO, M. Usos pouco conhecidos de plantas daninhas como companheiras, repelentes, inseticida, iscas, moluscolicidas e nematicidas. Informe Agropecuário, Belo Horizonte, v. 13, n. 150, p. 3033, 1988.

LARCHER, W. Ecofisiologia vegetal. São Carlos: RiMa Artes e Textos, 2000. $531 \mathrm{p}$.

LORENZI, H.; MATOS, F. J. A. Plantas medicinais no Brasil: nativas e exóticas. Nova Odessa: Plantarum, 2002. $511 \mathrm{p}$.

MORAES, A. A.; VIEIRA, M. C.; HEREDIA ZÁRATE, N. A. Produção de capuchinha e repolho, cultivadas solteiras e consorciadas, com e sem cama de frango semidecomposta, incorporada no solo. Horticultura Brasileira, Brasília, v. 23, n. 2, 2005. Suplemento. CD-ROM.

NUNES, M. U. C.; ANDRADE, L. N. T.; MORAES FILHO, M.; CUNHA, A. O.; MATA, S. S. da. Comportamento de cultivares de repolho em sistema orgânico de produção. Horticultura Brasileira, Brasília, v. 22, n. 2, 2004. Suplemento. CD-ROM.

RIBEIRO JUNIOR, J. I. Análise estatística no SAEG. Viçosa: UFV, 2001. 301 p.
SANGALLI, A.; VIEIRA, M. C.; HEREDIA ZÁRATE, N. A. Resíduos orgânicos e nitrogênio na produção de biomassa da capuchinha (Tropaeolum majus L.) Jewel. Ciência e Agrotecnologia, Lavras, v. 28, n. 4, p. 831-839, 2004.

SILVA JÚNIOR, A. A. Repolho: fitologia, fitotecnia, tecnologia alimentar e mercadologia. Florionópolis: EMPASC, 1989. 295 p.

SILVA, N. F. da. Consórcio de hortaliças. In: HEREDIA, M. C. V. de; CASALI, V. W. D. (Coords.). Seminários de olericultura. Viçosa: UFV, 1983. v. 3, p. 1-19.

SOUZA, V. C.; LORENZI, H. Botânica sistemática: guia ilustrado para identificação das famílias de Angiospermas da flora brasileira, baseado em APG II. Nova Odessa: Instituto Plantarum, 2005. $640 \mathrm{p}$.

SULLIVAN, P. Intercropping principles and production practices. 1998. Disponível em: <http://www.attra.org./attrapub/intercrop.htm\#abstract>. Acesso em: 10 ago. 2003.

ZANETTI, G. D. Tropaeolum majus L.: morfo-histologia, fitoquímica, ação antimicrobiana e toxicidade. $2001.93 \mathrm{f}$. Dissertação (Mestrado em Ciência e Tecnologia Farmacêutica) - Universidade Federal de Santa Maria, Santa Maria, 2001. 